Article

\title{
Cobaloximes as Building Blocks in Halogen-Bonded Cocrystals
}

\author{
Nikola Bedeković ${ }^{1}(0)$, Valentina Martinez ${ }^{1,2}$, Edi Topić $^{1}$, Vladimir Stilinović ${ }^{1, *}$ and \\ Dominik Cinčić ${ }^{1, * \mathbb{B}}$
}

1 Department of Chemistry, Faculty of Science, University of Zagreb, Horvatovac 102A, 10000 Zagreb, Croatia; nbedekovic@chem.pmf.hr (N.B.); vmartin@irb.hr (V.M.); edi.topic@chem.pmf.hr (E.T.)

2 Laboratory for Green Synthesis, Ruđer Bošković Institute, Bijenička cesta 54, 10000 Zagreb, Croatia

* Correspondence: vstilinovic@chem.pmf.hr (V.S.); dominik@chem.pmf.hr (D.C.); Tel.: +385-1-4606-371 (V.S.); +385-1-4606-362 (D.C.)

Received: 29 April 2020; Accepted: 18 May 2020; Published: 21 May 2020

\begin{abstract}
In this work, we explore the halogen-bonded cocrystallization potential of cobaloxime complexes in the synthesis of cocrystals with perhalogenated benzenes. We demonstrate a strategy for synthesizing halogen-bonded metal-organic cocrystals by utilizing cobaloximes whose pendant bromide group and oxime oxygen enable halogen bonding. By combining three well-known halogen bond donor molecules differing in binding geometry and composition with three cobaloxime units, we obtained a total of four previously unreported cocrystals. Single crystal X-ray diffraction experiments showed that the majority of obtained cocrystals exhibited the formation of the targeted $\mathrm{I} \cdots \mathrm{O}$ and $\mathrm{I} \cdots \mathrm{Br}$ motives. These results illustrate the potential of cobaloximes as halogen bond acceptors and indicate that this type of halogen bond acceptors may offer a novel route to metal-organic halogen-bonded cocrystals.
\end{abstract}

Keywords: halogen bonding; cobaloximes; coordination compounds; cocrystals; mechanochemistry

\section{Introduction}

Since the revival of research into halogen bonding [1-3], there have been two main avenues of research: the fundamental study of the nature of halogen bonding, and the application of halogen bonding in the design of new materials. The results of the former (such as the predominantly electrostatic [4] and occasionally covalent [5-8] nature of the interaction, comparison with hydrogen bonding [9-11], the possibility of bifurcation [12-14], and metal and metalloid atoms as acceptors [15,16]) have contributed to a considerable extension of the possibilities for preparing various halogen-bonded functional materials $[17,18]$, such as liquid crystals [19,20], anion receptors [21,22], photoluminescent [23, 24] and photoreactive materials, and gelators [25-27].

The majority of research into halogen-bonded materials, however, has been dealing with purely organic materials - both halogen donor and acceptor being organic molecules. As introducing metal atoms into a supramolecular material can significantly expand the possibilities of adding and controlling additional properties (such as magnetism and conductivity) [28,29], the use of halogen bonding in the crystal engineering of metal-organic materials has been an attractive challenge over the past decade [30-40]. While there have been substantial studies into halogen bonding in single component metal-organic solids [30-41], synthesis of multi-component materials based on halogen-bonded metal-organic components has been receiving much less attention. Particularly scarce are studies involving cocrystals of neutral metal-organic components acting as halogen bond acceptors [42-47]. The most promising building blocks to date have been metal coordination complexes comprised of pendant acceptor groups such as halogenide ligands [46,47], chelating ligands such as imines [43], 
$\beta$-dicarbonyl compounds [14] and ligands with additional (non-coordinating) electron rich atoms or groups such as morpholine or thiomorpholine [48,49], which can form cocrystals with halogen bond donors, such as perfluorinated iodobenzenes.

A potentially interesting series of targets for synthesizing such cocrystals are cobaloximes (Scheme 1). These compounds were originally studied as analogues of cobalamine (vitamin B12) [50,51], but more recently have been drawing considerable attention as starting materials for the formation of organocobalt compounds [52,53], as well as catalysts for low-energy production of hydrogen [53-55]. As they can be modified by the addition of various substituents on the pyridine ring, as well as by using different anionic ligands $(\mathrm{X})$, they represent a vast and versatile group of compounds with tunable structures and properties. A cursory search of the Cambridge Structural Database (CSD) [56] based on oxime complexes of any transition metal resulted in 1521 hits; 191 of those are for structures of the $\mathrm{MX}(\mathrm{ox})_{2}$ type $(\mathrm{X}=$ halogen atom; ox = any oxime ligand). Restraining the search further, to Co complexes, resulted in 152 hits. Of those, there are no entries corresponding to halogen-bonded cocrystals, although there has been a report of halogen bonding in single-component crystals of cobaloximes with bromopyridine ligands [57]. Furthermore, a survey based on the ability of any transition metaloxime complex to act as a halogen bond acceptor with haloperfluorinated benzenes as halogen bond donors resulted in no hits.

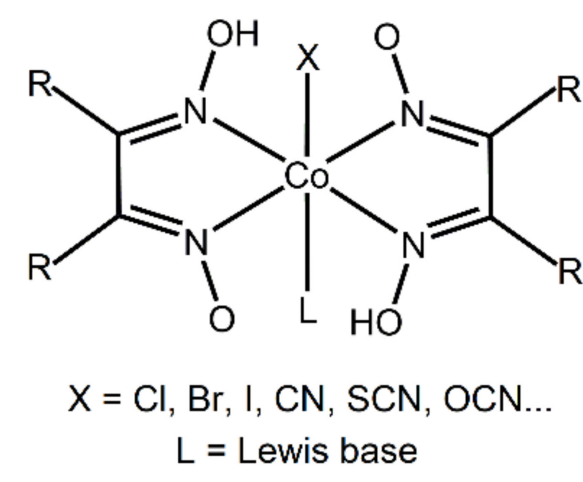

Scheme 1. General structure of cobaloximes.

In this work, we explored the ability to form halogen-bonded cocrystals with cobaloximes as halogen bond acceptors. For this purpose, we prepared three different cobaloxime derivatives (Scheme 2), which contain a pair of dimethylglyoximate anions, and one bromide anion coordinated to the metal center, and different pyridine ligands bonded to the axial coordination site. Their pendant and different functional groups enable halogen bonding: oxygen atoms on the oxime ligand, the coordinated bromine atom, as well as the $\pi$-system and the hydroxyl substituents of the pyridine ring can all act as halogen bond acceptor sites. For cocrystal synthesis, as halogen bond donors, we selected a series of perhalogenated benzenes that differ in the number and positions of donor atoms: 1,2-diiodotetrafluorobenzene (12tfib), 1,4-diiodotetrafluorobenzene (14tfib) and 1,4-dibromotetrafluorobenzene (14tfbb), Scheme 1. Additionally, we wanted to observe whether the additional hydrogen bond donor functionality introduced through the hydroxypyridine ligands would hinder the formation of the desired halogen bond. Thus, we prepared three cobaloxime complexes. Complex I contained an unsubstituted pyridine molecule that does not contain any functional groups prone to creating additional noncovalent interactions. On the other hand, 3- and 4-hydroxypyridine were present in the complexes II and III, respectively, which may act as hydrogen bond donors and form a wide range of disparate supramolecular motifs. The introduction of a hydroxyl group on the pyridine also affects the hydrogen (and halogen) bond acceptor potential of the metal complex molecule: in I the available acceptor sites are the four oxime oxygen atoms and the bromide ligand, while II and III can additionally form bonds via the hydroxyl oxygen atoms. 


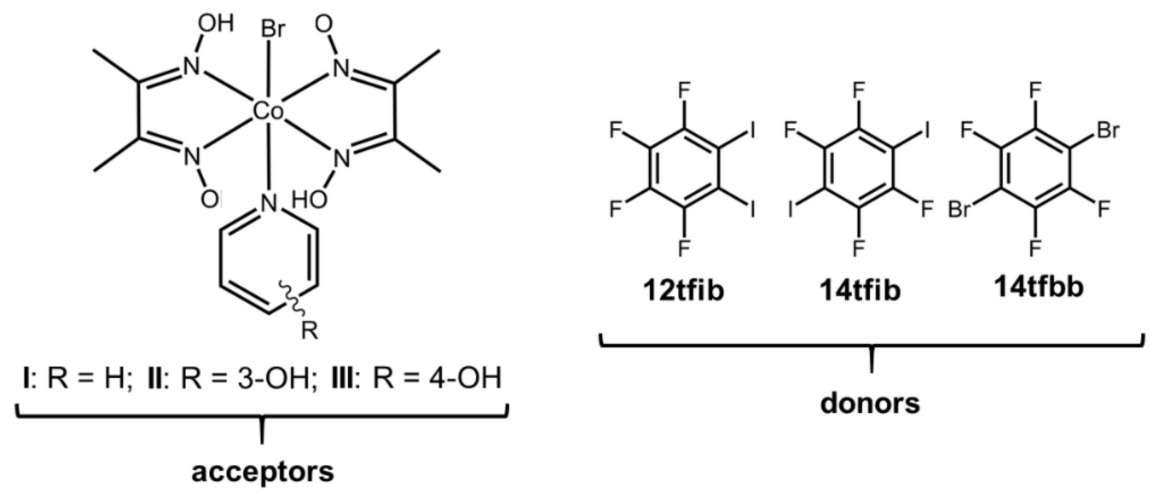

Scheme 2. Halogen bond donors and acceptors used in this study.

\section{Materials and Methods}

\subsection{Synthesis of Metal Complexes}

Metal complexes (Figures S1 and S2 in Supplementary Materials) were prepared as follows: cobalt(II) acetate dihydrate (Sigma-Aldrich Chemie GmbH, Taufkirchen, Germany) (0.82 g) was dissolved in hot ethanol (Sigma-Aldrich Chemie GmbH, Taufkirchen, Germany) (4.0 mL), and then concentrated hydrobromic acid (Sigma-Aldrich Chemie GmbH, Taufkirchen, Germany) was added $(380 \mu \mathrm{L})$-solution A. Dimethylglyoxime (Sigma-Aldrich Chemie GmbH, Taufkirchen, Germany) (Hdmg; $0.78 \mathrm{~g}$ ) and 3-hydroxypyridine or 4-hydroxypyridine (Sigma-Aldrich Chemie GmbH, Taufkirchen, Germany) (0.32 g) were dissolved in hot ethanol (Alkaloid, Skopje, Republic of North Macedonia) (10 mL), and afterwards, triethylamine (Sigma-Aldrich Chemie GmbH, Taufkirchen, Germany) was added (1.0 mL)—solution B. Solutions A and B were mixed in a test tube, and the resulting solution was oxidized by passing air through the mixture. After several hours, brown precipitates of the corresponding cobaloxime complexes formed and were then filtered off. Single crystals of I and II were obtained after dissolving $30 \mathrm{mg}$ of complex in $2.0 \mathrm{~mL}$ of a hot mixture of tetrahydrofuran (Sigma-Aldrich Chemie GmbH, Taufkirchen, Germany) and water (Zagrebački holding, Zagreb, Croatia) (volume ratio 3:1) and the subsequent cooling and solvent evaporation at room temperature for 2 days. All crystallization experiments for III resulted in crystals that were not suitable for the X-ray diffraction experiment.

\subsection{Synthesis of Cocrystals}

In order to examine the ability of the prepared compounds I, II and III to form cocrystals with halogen bond donors (12tfib, 14tfib, and 14tfbb), the obtained complexes and donors were ground in 1:1 and 2:1 stoichiometric ratios, with the addition of small amounts of nitromethane (Sigma-Aldrich Chemie GmbH, Taufkirchen, Germany) $(20 \mu \mathrm{L})$. The obtained powders were then characterized by XRPD to test whether a new phase had formed. The grinding experiments were conducted in a Retsch MM200 ball mill (Retsch, Haan, Germany) using $10 \mathrm{~mL}$ stainless steel jars and two stainless steel balls ( $5 \mathrm{~mm}$ in diameter) for $30 \mathrm{~min}$, under normal laboratory conditions (40-60\% relative humidity and temperature $c a .25^{\circ} \mathrm{C}$ ). Masses and volumes of the reactants used in the mechanochemical synthesis of cocrystals are given in Table S1 and Table S2 in the Supplementary Materials.

Single crystals of compounds whose formation was confirmed by the mechanochemical experiments were prepared by crystallization from the solution. The corresponding halogen bond donors and metal-organic complexes were dissolved in $3.0 \mathrm{~mL}$ of a hot mixture of tetrahydrofuran and acetonitrile (volume ratio 2:1), whereupon the solutions were left to cool and evaporate (experimental details are given in the Supplementary Materials). Crystals suitable for single crystal X-ray diffraction experiments appeared after three to five days. ORTEP plots of the obtained compounds are shown in Figures S3-S6 in Supplementary Materials. 


\subsection{X-Ray Diffraction Measurements}

Single crystal X-ray diffraction experiments were performed using an Oxford Diffraction Xcalibur Kappa CCD X-ray diffractometer (Oxford Diffraction Ltd., Abingdon, UK) with graphite-monochromated $\operatorname{MoK}_{\alpha}(\lambda=0.71073 \AA)$ radiation. The data sets were collected using the $\omega$-scan mode over the $2 \theta$-range up to $54^{\circ}$. Programs CrysAlis CCD and CrysAlis RED were employed for data collection, cell refinement, and data reduction [58,59]. The structures were solved by direct methods and refined using the SHELXS (Version 2013, Göttingen, Germany) and SHELXL programs (Version 2013, Göttingen, Germany), respectively [60,61]. The structural refinement was performed on $F^{2}$ using all data. The hydrogen atoms were placed in calculated positions and treated as riding on their parent atoms $\left[\mathrm{C}-\mathrm{H}=0.93 \AA\right.$ and $U_{\text {iso }}(\mathrm{H})=1.2 U_{\text {eq }}(\mathrm{C}) ; \mathrm{C}-\mathrm{H}=0.97 \AA$ and $U_{\text {iso }}(\mathrm{H})=$ $\left.1.2 U_{\text {eq }}(C)\right]$. All calculations were performed using the WinGX crystallographic suite of programs [62]. The figures were prepared using Mercury (Version 4.3.1., CCDC, Cambridge, UK) [63]. Crystallographic data of the prepared compounds are shown in Table S3 in Supplementary Materials.

Powder X-ray diffraction (XRPD) experiments on the samples were performed on a PHILIPS PW $1840 \mathrm{X}$-ray diffractometer (Philips Analytical, Almelo, The Netherlands) with $\mathrm{CuK} K_{\alpha 1}(1.54056 \AA)$ radiation at $40 \mathrm{~mA}$ and $40 \mathrm{kV}$. The scattered intensities were measured with a scintillation counter. The angular range was from $5^{\circ}$ to $45^{\circ}(2 \theta)$ with a continuous step size of $0.02^{\circ}$ and measuring a time of $0.5 \mathrm{~s}$ per step. Data collection was performed using the program package Philips X'Pert (Version 1.3e, Philips Analytical, Almelo, The Netherlands) [64] and analysed in X'Pert HighScore Plus (Version 2.2, Malvern Panalytical, Malvern Worcestershire, UK) [65]. Comparisons of the measured and calculated diffractograms for cocrystals are shown in Figures S7-S13 in the Supplementary Materials).

\subsection{Thermal Analysis}

Differential scanning calorimetry (DSC) measurements were performed on a Mettler-Toledo DSC823e module (Mettler Toledo, Greifensee, Switzerland) in sealed aluminium pans ( $40 \mu \mathrm{L})$ with three pinholes in the lid, heated in a stream of nitrogen $\left(150 \mathrm{~mL} \cdot \mathrm{min}^{-1}\right)$ at a heating rate of $10^{\circ} \mathrm{C} \cdot \mathrm{min}^{-1}$.

Thermogravimetric measurements (TG) were performed on a Metler-Toledo TGA/SDTA 851e module (Mettler Toledo, Greifensee, Switzerland). Samples were placed in sealed $40 \mu \mathrm{L}$ aluminium pans with three pinholes and heated from 25 to $500^{\circ} \mathrm{C}$, at a rate of $10{ }^{\circ} \mathrm{C} \cdot \mathrm{min}^{-1}$ under nitrogen flow of $150 \mathrm{~mL} \cdot \mathrm{min}^{-1}$.

Data collection and analysis were performed using the program package STARe Software (Version 15.00, Mettler Toledo, Greifensee, Switzerland) [66]. TG and DSC thermograms of the prepared compounds are shown in Figures S14-S25 in Supplementary Materials.

\subsection{Calculations}

Hirshfeld surfaces and fingerprint plots were calculated using CrystalExplorer [67] (Version 3.1., University of Western Australia, Crawley, Australia). Hirshfeld surfaces and fingerprint plots are shown in Figures S26-S31 in Supplementary Materials.

\section{Results and Discussion}

\subsection{Syntheses of Cocrystals}

The large difference in solubility between the used metal-organic complexes and halogen bond donors in most organic solvents created a considerable challenge in the synthesis of cocrystals by crystallization from the solution. Mechanochemical synthesis stood out as a better method for the preparation of this class of compounds, since dissolving the reactants was not a prerequisite for successful cocrystal synthesis. Screening experiments have shown that five out of a total of nine reactant combinations resulted in the formation of new crystalline products, as evidenced by the appearance of new Bragg reflections in the PXRD patterns upon milling (Figures S7-S13). Grinding experiments of the complex I and halogen bond donors have resulted in cocrystal formation only with 
12tfib. Furthermore, a total of four new cocrystals of complexes II and III were prepared with linear halogen bond donors 14tfib and $\mathbf{1 4 t f b b}$. Subsequent single crystal X-ray diffraction experiments on samples grown from the solution have shown that four products are halogen-bonded cocrystals of the following compositions: (I)(12tfib), (II) $)_{2}(\mathbf{1 4 t f i b}),(\text { III })_{2}(\mathbf{1 4 t f i b})$ and $(\mathrm{III})_{2}(\mathbf{1 4 t f b b})$.

\subsection{Structural Analysis}

Although all three metal complexes were successfully prepared as fine brown powders and characterized by XRPD and thermal analysis, molecular and crystal structures were successfully determined only for I and II (Figure 1a,c, Figures S1 and S2; Table S3). In both complexes, the metal cation is hexacoordinated, with donor atoms placed at the vertices of a distorted octahedron. The complexes are further stabilized by two intramolecular $\mathrm{O}-\mathrm{H} \cdots \mathrm{O}$ hydrogen bonds, which is a specific and well known feature of this class of compounds. In II, the molecules are connected by hydrogen bonding into chains by $\mathrm{O}-\mathrm{H} \cdots \mathrm{O}$ interactions, in which the hydroxyl group of 3-hydroxypyridine is the hydrogen bond donor and the oxime oxygen atom is the hydrogen bond acceptor $(d=2.715(5) \AA, \angle(\mathrm{O}-\mathrm{H} \cdots \mathrm{O})=$ $144.3(5)^{\circ}$; Figure $\left.1 \mathrm{~d}\right)$. Chains are then connected in the $3 \mathrm{D}$ structure by $\mathrm{C}-\mathrm{H} \cdots \mathrm{O}$ and $\mathrm{C}-\mathrm{H} \cdots \pi$ interactions. In the crystal structure of complex I, molecules are connected into chains by weak $\mathrm{C}_{\text {methyl }}-\mathrm{H} \cdots \mathrm{O}$ contacts $\left(d=3.261(7) \AA, \angle(C-H \cdots O)=127.7(2)^{\circ}\right)$ and further into the 3D structure by C-H $\cdots \mathrm{O}$ contacts, where $\mathrm{C}-\mathrm{H}$ is part of the pyridine ring or methyl group of a dmg ligand (Figure $1 \mathrm{~b}$ ). This type of molecular interconnection is expected due to the absence of functional groups that could participate in stronger and more directional interactions.

a)

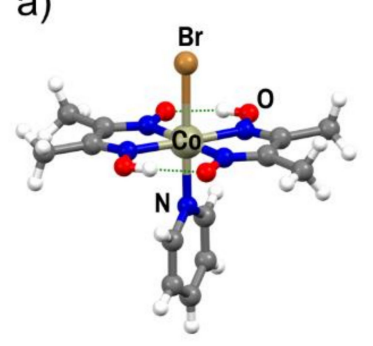

C)

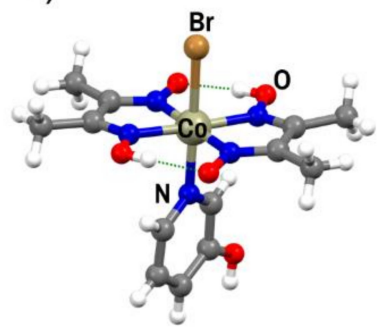

b)

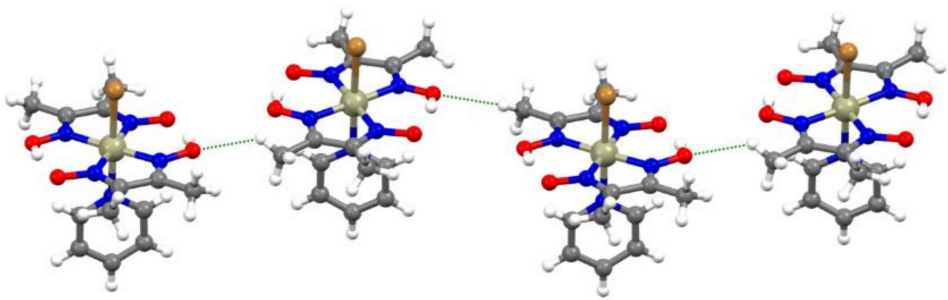

d)

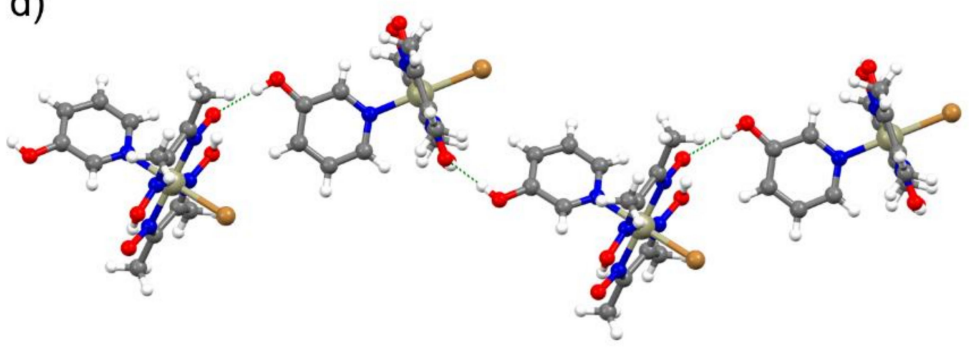

Figure 1. (a) Molecular structure of cobaloxime $\mathbf{I}$; (b) $\mathrm{C}-\mathrm{H} \cdots \mathrm{O}$ contacts in the crystal structure of I; (c) the molecular structure of II; (d) O-H $\cdots$ O hydrogen-bonded chain in the crystal structure of II.

The linear halogen bond donors (14tfib and 14tfbb) preferentially form 2:1 cocrystals, while the "bent" and sterically hindered 12tfib forms cocrystals of 1:1 stoichiometry with the used metal-organic units. In 2:1 cocrystals, molecules are connected into discrete complexes, while chains have been found in the cocrystal with the 1:1 donor/acceptor ratio. Halogen bond parameters in crystal structures of the prepared cocrystals are shown in Table 1. 
Table 1. Halogen bond lengths, angles and relative shortening in crystal structures of the prepared cocrystals $\left(\mathrm{X}=\mathrm{I}\right.$ for 12tfib and 14tfib; $\mathrm{X}=\mathrm{Br}$ for 14tfbb). r.s. $=1-\left[d(\mathrm{X} \cdots \mathrm{Y}) /\left(r_{\mathrm{vdW}, \mathrm{X}}+r_{\mathrm{vdW}, \mathrm{Y}}\right)\right]$.

\begin{tabular}{ccccc}
\hline Parameter & $\mathbf{( I )}(\mathbf{1 2 t f i b )}$ & $\mathbf{( I I )}_{\mathbf{2}} \mathbf{( 1 4 t f i b )}$ & $\mathbf{( I I I )}_{\mathbf{2}} \mathbf{( 1 4 t f i b )}$ & $\mathbf{( I I I )}_{\mathbf{2}} \mathbf{( 1 4 t f b b )}$ \\
\hline$d(\mathrm{X} \cdots \mathrm{O}) / \AA$ & $3.126(7)$ & $2.936(5)$ & $\times$ & $3.079(4)$ \\
$r . s .(\mathrm{X} \cdots \mathrm{O}) / \%$ & 10.7 & 16.1 & $\times$ & 8.6 \\
$\angle(\mathrm{C}-\mathrm{X} \cdots \mathrm{O}) /{ }^{\circ}$ & $164.6(3)$ & $169.2(2)$ & $\times$ & $172.4(2)$ \\
\hline$d(\mathrm{X} \cdots \mathrm{Br}) / \AA$ & $3.443(2)$ & $\times$ & $3.415(1)$ & $\times$ \\
$r . s .(\mathrm{X} \cdots \mathrm{Br}) / \%$ & 10.1 & $\times$ & 10.8 & $\times$ \\
$\angle(\mathrm{C}-\mathrm{X} \cdots \mathrm{Br}) /^{\circ}$ & $166.4(3)$ & $\times$ & $170.5(2)$ & $\times$ \\
\hline$d(\mathrm{X} \cdots \mathrm{C}(\pi) / \AA$ & $\times$ & $\times$ & $3.654(6)$ & $\times$ \\
$r . s .(\mathrm{X} \cdots \mathrm{C}(\pi) / \%$ & $\times$ & $\times$ & 0.7 & $\times$ \\
$\angle\left(\mathrm{C}-\mathrm{X} \cdots \mathrm{C}(\pi) /^{\circ}\right.$ & $\times$ & $\times$ & $157.8(2)$ & $\times$ \\
\hline
\end{tabular}

In the formula unit of (I)(12tfib), a halogen bond between one iodine atom and the deprotonated oxime oxygen was found (r.s. $(\mathrm{I} \cdots \mathrm{O})=11.4 \%$; Figure $2 \mathrm{a}$ and Figure $\mathrm{S} 3)$. The second iodine atom of the 12tfib molecule was found to form a somewhat longer halogen bond with the bromine atom coordinated to the metal center (r.s. $(\mathrm{I} \cdots \mathrm{Br})=2.5 \%)$. This interaction connects units of $(\mathbf{I})(\mathbf{1 2 t}$ tfib) into halogen-bonded zig-zag chains (Figure 3). Despite considerable differences in length, both the $\mathrm{C}-\mathrm{I} \cdots \mathrm{O}$ and the $\mathrm{C}-\mathrm{I} \cdots \mathrm{Br}$ halogen bond are roughly linear and have similar $\mathrm{C}-\mathrm{I} \cdots \mathrm{Y}$ angles. As expected, no other strong and directional noncovalent interactions have been observed in the crystal structure of (I)(12tfib), therefore chains are linked into 2D networks, and further into the 3D structure, by weak $\mathrm{C}-\mathrm{H} \cdots \mathrm{F}$ interactions.

a)

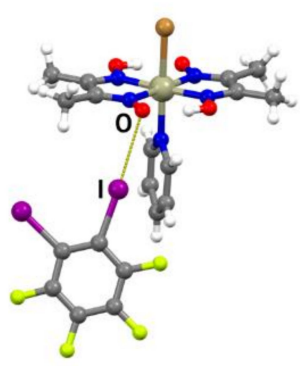

b)

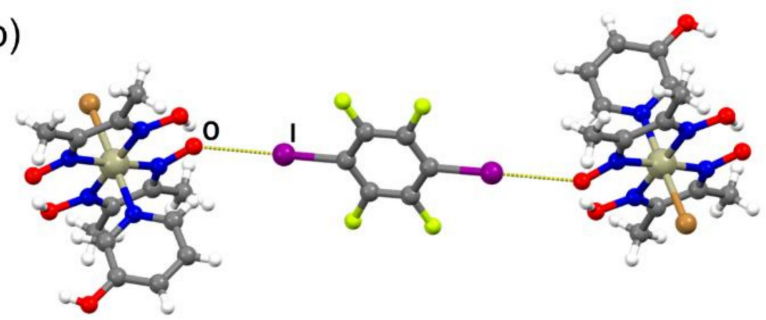

c)

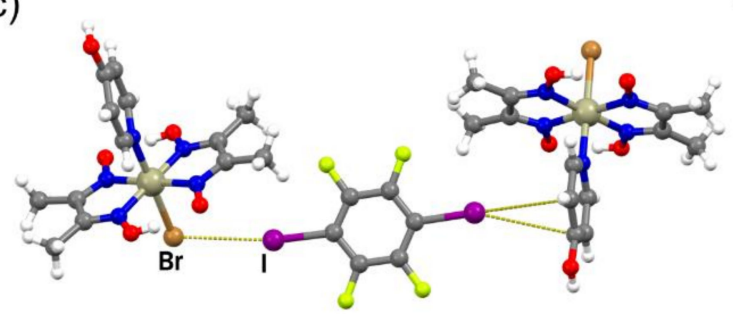

d)

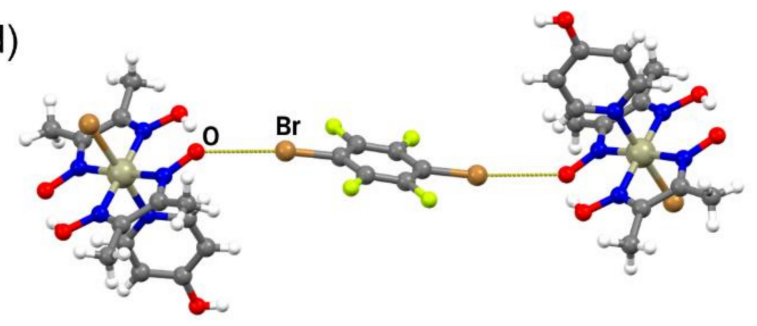

Figure 2. Discrete halogen-bonded units in (a) (I)(12tfib); (b) (II $)_{2}(\mathbf{1 4 t f i b ) ; ~ ( c ) ~ ( I I I ) ~})_{2}(\mathbf{1 4 t f i b})$; (d) $(\text { III })_{2}(\mathbf{1 4 t f b b})$.

Compound II forms cocrystals with two linear halogen bond donors: 14tfib and 14tfbb. The $(\mathbf{I I})_{2}$ (14tfib) cocrystal consists of formula units formed by two symmetrically equivalent halogen bonds between iodine and oxime oxygen atoms (Figure $2 \mathrm{~b}$ and Figure S4). The halogen bonds are relatively short $($ r.s. $(\mathrm{I} \cdots \mathrm{O})=16.1 \%)$ and linear $\left(\angle(\mathrm{C}-\mathrm{I} \cdots \mathrm{O})=169.2^{\circ}\right)$, which is to be expected in cocrystals where 14tfib is the halogen bond donor. The resulting halogen-bonded supramolecular complexes are connected into hydrogen-bonded chains by the metal-organic unit homosynthon $R_{2}^{2}(16)$, in which the 3-hydroxypyridine hydroxyl group is the hydrogen bond donor and the deprotonated oxime oxygen is the hydrogen bond acceptor $\left(d(\mathrm{O} \cdots \mathrm{O})=2.667(7) \AA ; \angle(\mathrm{O}-\mathrm{H} \cdots \mathrm{O})=165.3^{\circ}\right)$ (Figure 4). Hydrogen-bonded chains are connected in the 3D structure by C-H...F interactions. The crystal structure of $(\mathbf{I I})_{2}(\mathbf{1 4 t} \mathbf{t f b b})$ 
has not been determined in this study, but the evident similarity of $(\mathbf{I I})_{2}(\mathbf{1 4 t f i b})$ and $(\mathbf{I I})_{2}(\mathbf{1 4 t f f b b})$ powder patterns indicate that these two compounds are isostructural. Consequently, $(\mathbf{I I})_{2}(\mathbf{1 4 t f b b})$ also consists of halogen-bonded formula units of 2:1 halogen bond acceptor: donor stoichiometry, with two identical Br...O halogen bonds.

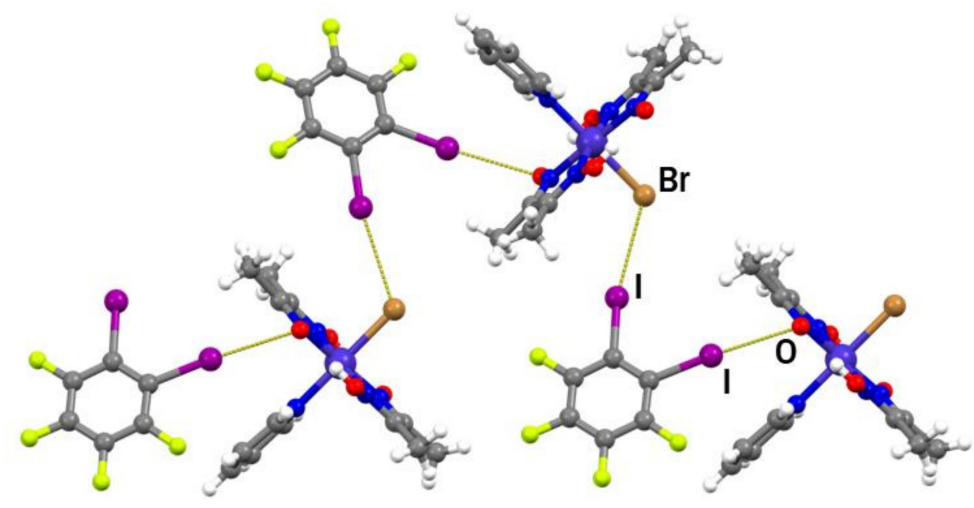

Figure 3. Halogen-bonded chain in the crystal structure of (I)(12tfib).

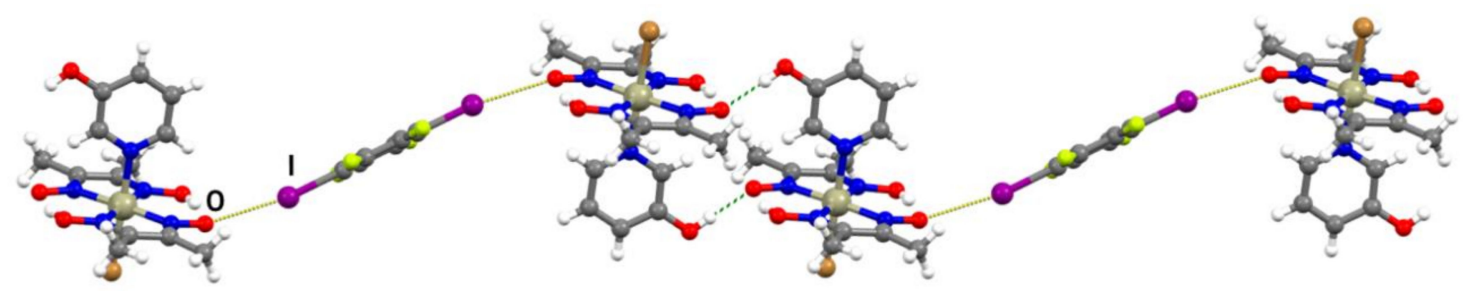

Figure 4. Halogen-bonded units of $(\mathbf{I I})_{2}$ (14tfib) interconnected by $\mathrm{O}-\mathrm{H} \cdots \mathrm{O}$ hydrogen-bonded homosynthons into a chain.

Compound III also forms cocrystals with both linear halogen bond donors used in this work, but, unlike cocrystals of II, they are not isostructural. The (III $)_{2}(\mathbf{1 4 t f i b})$ cocrystal consists of metal-organic molecules bonded to 14tfib by two nonequivalent $\mathrm{C}-\mathrm{I} \cdots \mathrm{Br}$ and $\mathrm{C}-\mathrm{I} \cdots \pi$ halogen bonds (Figure $2 \mathrm{c}$ and Figure S5). Surprisingly, although complex III contains many other reliable binding sites, one of the available donor atoms participates in halogen bonding with the $\pi$-system of the 4-hydroxypyridine ring. This observation could be explained by the electron-donating nature of the hydroxyl group, which increases the electron density in the aromatic ring and enhances the halogen bond acceptor ability of the $\pi$-system. Nevertheless, the $\mathrm{I} \cdots \pi$ halogen bond is extremely long $($ r.s. $=0.7 \%$ ) with a small $\mathrm{C}-\mathrm{I} \cdots \mathrm{C}(\pi)$ angle, indicating that it was mainly formed as a result of molecular close packing in the crystal $\left(C_{K}=66.2 \%\right)$. Halogen-bonded molecular complexes in (III $)_{2}(\mathbf{1 4 t f i b})$ are connected into chains by hydrogen bonding between 4-hydroxypyridine hydroxyl groups and deprotonated oxime oxygen atoms $\left(d(\mathrm{O} \cdots \mathrm{O})=2.538(5) \AA ; \angle(\mathrm{O}-\mathrm{H} \cdots \mathrm{O})=157.6^{\circ} ;\right.$ Figure 5$)$ and such chains are connected in the 3D structure by $\pi$-stacking and $\mathrm{C}-\mathrm{H} \cdots \mathrm{F}$ interactions.

In the (III $)_{2}(\mathbf{1 4 t f b b})$ supramolecular complexes, the $\mathbf{1 4 t f b b}$ molecule participates in two equivalent $\mathrm{Br} \cdots \mathrm{O}$ halogen bonds in which the deprotonated oxime oxygen atom is the halogen bond acceptor (the same motif as the one found in (II) $)_{2}(\mathbf{1 4 t f i b})$; Figure $2 \mathrm{~b}$ and Figure S6). In comparison with $(\mathbf{I I})_{2}(\mathbf{1 4 t f i b})$, the formed halogen bonds are slightly longer (r.s. $\left.(\mathrm{Br} \cdots \mathrm{O})=8.6 \%\right)$, but more linear (Table 1). The halogen-bonded complexes $(\mathbf{I I I})_{2}(\mathbf{1 4 t f b b})$ are connected into chains by $\mathrm{O}-\mathrm{H}$-..O hydrogen bonds between 4-hydroxypyridine hydroxyl groups and the deprotonated oxime oxygen atom not involved in halogen bonding $\left(d(\mathrm{O} \cdots \mathrm{O})=2.629(5) \AA ; \angle(\mathrm{O}-\mathrm{H} \cdots \mathrm{O})=162.1^{\circ}\right)$, with 14 tfbb molecules bridging between the chains (Figure 6). This structure is additionally stabilized by close contacts between the coordinated bromide of III with the electron-depleted carbon atoms (bonded to the bromine) of $\mathbf{1 4 t f b b}$

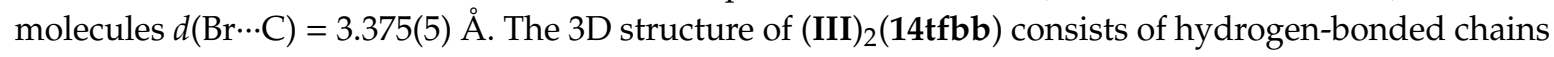
interconnected by weak $\mathrm{C}-\mathrm{H} \cdots \mathrm{O}$ and $\mathrm{C}-\mathrm{H} \cdots \mathrm{Br}$ interactions. 


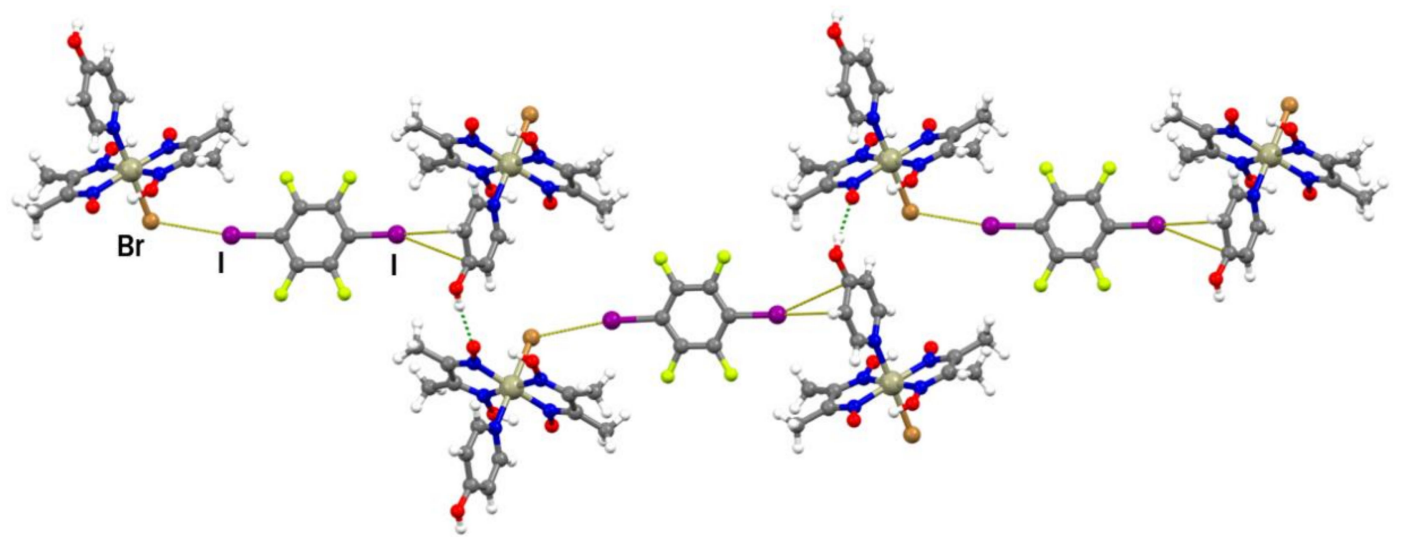

Figure 5. Halogen-bonded units of $(\mathrm{III})_{2}(\mathbf{1 4 t f i b})$ connected by $\mathrm{O}-\mathrm{H} \cdots \mathrm{O}$ hydrogen bonds into a chain.

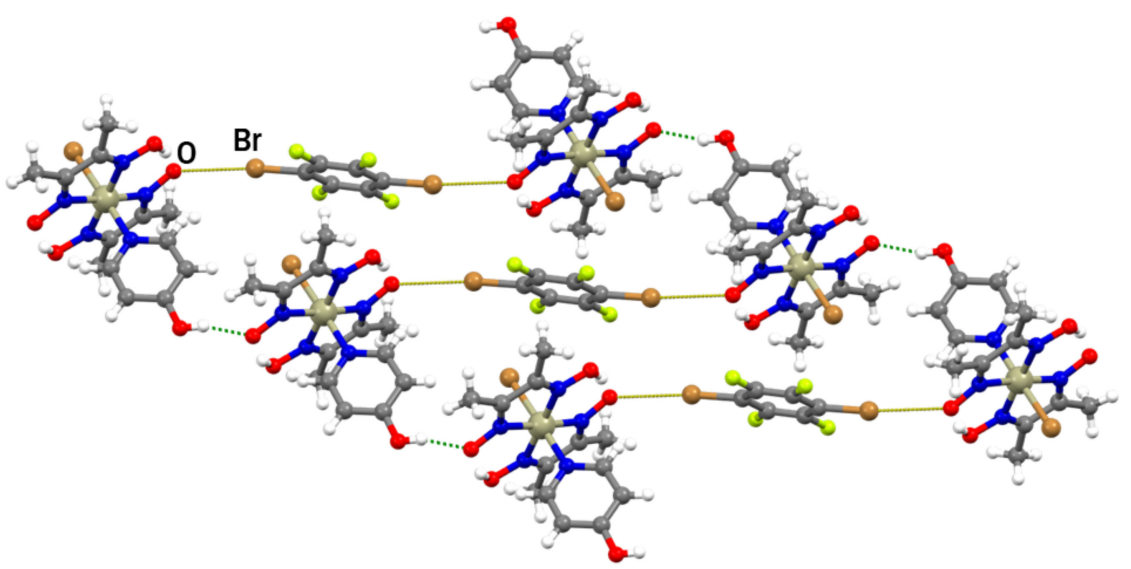

Figure 6. Halogen-bonded units of $(\mathbf{I I I})_{2}(\mathbf{1 4} \mathbf{t f b b})$ connected by $\mathrm{O}-\mathrm{H} \cdots \mathrm{O}$ hydrogen-bonds into a chain.

\subsection{Thermal Analysis}

Upon heating, the obtained cocrystals decompose in two separate steps. The (I)(12tfib) cocrystal starts decomposing at the lowest temperature $\left(122^{\circ} \mathrm{C}\right)$ and is followed by $(\mathbf{I I})_{2}(\mathbf{1 4 t f i b})$ and $(\mathbf{I I I})_{2}(\mathbf{1 4 t f i b})$, for which the decomposition start values are quite similar $\left(184^{\circ} \mathrm{C}\right.$ and $188^{\circ} \mathrm{C}$, respectively). The highest decomposition temperature was measured for $(\mathbf{I I I})_{2}(\mathbf{1 4 t f b b})\left(201^{\circ} \mathrm{C}\right)$. Since this compound has the longest (weakest) halogen bond, its higher thermal stability could be ascribed to the higher value of the Kitaigorodskii crystal packing index $\left(C_{\mathrm{K}}=68.3 \%\right)$. Furthermore, during the heating of (II $)_{2}(\mathbf{1 4 t f i b})$ and (III $)_{2}$ (14tfib), intense and broad exothermic signals at $\approx 270{ }^{\circ} \mathrm{C}$ were observed. Similar exothermic signals are also present in the DSC thermograms of the pure complexes II and III, but they are much narrower and more intense than for corresponding cocrystals (Figures S14-S25).

\section{Conclusions}

The cocrystals prepared and described herein indicate that cobaloximes could serve as reliable building blocks for metal-organic halogen-bonded cocrystals. Of all the acceptor $\pi$-sites present in the metal-organic molecules used, the oxime oxygen atom stood out as the best halogen bond acceptor, since it was involved in halogen bonding in a total of three cocrystals. The coordinated bromine atom is a slightly weaker acceptor (the I...Br contact was found in two cocrystals), while the weakest one is the hydroxyl group of the coordinated pyridine molecule, which did not participate in halogen bonding with any of the used donors. In the (III) $)_{2}(\mathbf{1 4 t f i b})$ cocrystal, binding of the $\pi$-system to the donor atom was observed, resulting in the formation of an extremely long and relatively weak halogen bond, which is presumably a consequence of close packing of halogen-bonded complexes in the crystal structure. 
In this study, a very small sample of cobaloxime complexes was used, but their simple synthesis and the large number of possible derivatives (with different halogenides or pseudohalogenides, as well as pyridine derivatives) could stimulate further research into halogen bonding in such systems. For this reason, we believe that this research has created new opportunities for the study of halogen-bonded cocrystals with metal-organic building blocks.

Supplementary Materials: The following are available online at http://www.mdpi.com/1996-1944/13/10/2370/s1, Figure S1. Molecular structure of I showing the atom-labelling scheme. Displacement ellipsoids are drawn at the $50 \%$ probability level; Figure S2. Molecular structure of II showing the atom-labelling scheme. Displacement ellipsoids are drawn at the 50\% probability level; Figure S3. Molecular structure of (I)(12tfib) showing the atom-labelling scheme. Displacement ellipsoids are drawn at the 50\% probability level; Figure S4. Molecular structure of $(\mathrm{II})_{2}(14 \mathrm{tfib})$ showing the atom-labelling scheme. Displacement ellipsoids are drawn at the $50 \%$ probability level; Figure S5. Molecular structure of $(\mathrm{III})_{2}(14 \mathrm{tfib})$ showing the atom-labelling scheme. Displacement ellipsoids are drawn at the $50 \%$ probability level; Figure S6. Molecular structure of (III) $2(14 \mathrm{tfbb})$ showing the atom-labelling scheme. Displacement ellipsoids are drawn at the $50 \%$ probability level; Figure S7. Measured and calculated XRPD patterns of I; Figure S8. Measured and calculated XRPD patterns of (I)(12tfib); Figure S9. Measured and calculated XRPD patterns of II; Figure S10. Measured and calculated XRPD patterns of (II) $)_{2}(14 \mathrm{tfib})$; Figure S11. Measured XRPD patterns of $(\mathrm{II})_{2}(14 \mathrm{tfbb})$ and $(\mathrm{II})_{2}(14 \mathrm{tfib})$ and calculated XRPD pattern of (II) $)_{2}(14 \mathrm{tfib})$; Figure S12. Measured and calculated XRPD patterns of $(\mathrm{III})_{2}(14 \mathrm{tfib})$; Figure S13. Measured and calculated XRPD patterns of $(\mathrm{III})_{2}(14 \mathrm{tfbb})$; Figure S14. DSC thermogram of I; Figure S15. TG thermogram of I; Figure S16. DSC thermogram of (I)(12tfib); Figure S17. TG thermogram of (I)(12tfib); Figure S18. DSC thermogram of II; Figure S19. TG thermogram of II; Figure S20. DSC thermogram of (II) $)_{2}(14 \mathrm{tfib})$; Figure S21. TG thermogram of (II) $)_{2}(14 \mathrm{tfib})$; Figure S22. DSC thermogram of $(\mathrm{III})_{2}(14 \mathrm{tfib})$; Figure S23. TG thermogram of $(\mathrm{III})_{2}(14 \mathrm{tfib})$; Figure S24. DSC thermogram of $(\mathrm{III})_{2}(14 \mathrm{tfbb})$; Figure S25. TG thermogram of $(\mathrm{III})_{2}(14 \mathrm{tfbb})$; Table S1. Masses of the complexes (I, II, III) and donors (12tfib, 14tfib) used in the mechanochemical synthesis of cocrystals in 1:1 and 2:1 molar ratio. Experiments were performed by addition of $20 \mu \mathrm{L}$ of nitromethane in reaction mixture. Table S2. Masses of the complexes (I, II, III) and donor 14tfbb used in the mechanochemical synthesis of cocrystals in 1:1 and 2:1 molar ratio. Experiments were performed by addition of $20 \mu \mathrm{L}$ of nitromethane in reaction mixture. Table S3. An overview and crystallographic data of the prepared compounds. CCDC 1999040-1999045 contain crystallographic data for this paper. These data can be obtained free of charge from the Director, CCDC, 12 Union Road, Cambridge, CBZ 1EZ, UK (Fax: +44-1223-336033; email: deposit@ccdc.cam.ac.uk or www: http://www.ccdc.cam.ac.uk).

Author Contributions: Synthesis of the parent cobaloximes: N.B., E.T.; Cocrystal synthesis: N.B., E.T., V.M.; Mechanochemical experiments: V.M.; Characterization and single-crystal X-ray diffraction analysis: N.B., V.S.; Writing-original draft preparation: N.B., V.S. and D.C. All authors have read and agreed to the published version of the manuscript.

Funding: This research was supported by the Croatian Science Foundation under projects HRZZ-IP-2014-09-7367 and HRZZ-IP-2019-04-1868.

Acknowledgments: We are grateful to Vinko Nemec for helpful suggestions.

Conflicts of Interest: There are no conflicts to declare.

\section{References}

1. Legon, A.C. The halogen bond: An interim perspective. Phys. Chem. Chem. Phys. 2010, 12, $7736-7747$. [CrossRef]

2. Corradi, E.; Meille, S.V.; Messina, M.T.; Metrangolo, P.; Resnati, G. Halogen bonding versus hydrogen bonding in driving self-assembly processes. Angew. Chem. Int. Ed. 2000, 39, 1782-1786. [CrossRef]

3. Cardillo, P.; Corradi, E.; Lunghi, A.; Valdo Meille, S.; Teresa Messina, M.; Metrangolo, P.; Resnati, G. The N...I intermolecular interaction as a general protocol for the formation of perfluorocarbon-hydrocarbon supramolecular architectures. Tetrahedron 2000, 56, 5535-5550. [CrossRef]

4. Politzer, P.; Murray, J.S.; Clark, T. Halogen bonding: An electrostatically-driven highly directional noncovalent interaction. Phys. Chem. Chem. Phys. 2010, 12, 7748-7757. [CrossRef]

5. Eraković, M.; Cinčić, D.; Molčanov, K.; Stilinović, V. Crystallographic Charge Density Study of the Partial Covalent Nature of Strong N...Br Halogen Bonds. Angew. Chem. Int. Ed. 2019, 58, 15702-15706. [CrossRef]

6. Wolters, L.P.; Bickelhaupt, F.M. Halogen bonding versus hydrogen bonding: A molecular orbital perspective. ChemistryOpen 2012, 1, 96-105. [CrossRef]

7. Rosokha, S.V.; Stern, C.L.; Ritzert, J.T. Experimental and Computational Probes of the Nature of Halogen Bonding: Complexes of Bromine-Containing Molecules with Bromide Anions. Chem. Eur. J. 2013, 19, 8774-8788. [CrossRef] 
8. Weinberger, C.; Hines, R.; Zeller, M.; Rosokha, S.V. Continuum of covalent to intermolecular bonding in the halogen-bonded complexes of 1,4-diazabicyclo[2.2.2] octane with bromine-containing electrophiles. Chem. Commun. 2018, 54, 8060-8063. [CrossRef]

9. Stilinović, V.; Horvat, G.; Hrenar, T.; Nemec, V.; Cinčić, D. Halogen and hydrogen bonding between (N-halogeno)succinimides and pyridine derivatives in solution, the solid state and in silico. Chem. Eur. J. 2017, 23, 5244-5257.

10. Saccone, M.; Dichiarante, V.; Forni, A.; Goulet-Hanssens, A.; Cavallo, G.; Vapaavuori, J.; Terraneo, G.; Barret, J.C.; Resnati, G.; Metrangolo, P.; et al. Supramolecular hierarchy among halogen and hydrogen bond donors in light-induced surface patterning. J. Mater. Chem. C 2015, 3, 759-768. [CrossRef]

11. Aakeröy, C.B.; Panikkattu, S.; Chopade, P.D.; Desper, J. Competing hydrogen-bond and halogen-bond donors in crystal engineering. CrystEngComm 2013, 15, 3125-3136. [CrossRef]

12. Carletta, A.; Zbačnik, M.; Van Gysel, M.; Vitković, M.; Tumanov, N.; Stilinović, V.; Wouters, J.; Cinčić, D. Playing with isomerism: Cocrystallization of Isomeric $N$-Salicideneaminopyridines with Perfluorinated Compounds as Halogen Bond Donors and its Impact on Photochromism. Cryst. Growth Des. 2018, 18, 6833-6842. [CrossRef]

13. Carletta, A.; Zbačnik, M.; Vitković, M.; Tumanov, N.; Stilinović, V.; Wouters, J.; Cinčić, D. Halogen-bonded cocrystals of $\mathrm{N}$-Salicidene Schiff Bases and Iodoperfluorinated Benzenes: Hydroxyl Oxygen as Halogen Bond Acceptor. CrystEngComm 2018, 20, 5332-5339. [CrossRef]

14. Stilinović, V.; Grgurić, T.; Piteša, T.; Nemec, V.; Cinčić, D. Bifurcated and Monocentric Halogen Bonds in Cocrystals of Metal(II) Acetylacetonates with $p$-Dihalotetrafluorobenzenes. Cryst. Growth Des. 2019, 19, 1245-1256. [CrossRef]

15. Lisac, K.; Topić, F.; Arhangelskis, M.; Cepić, S.; Julien, P.A.; Nickels, C.W.; Morris, A.J.; Friščić, F.; Cinčić, D. Halogen-bonded cocrystallization with phosphorus, arsenic and antimony acceptors. Nat. Commun. 2019, 10, 61. [CrossRef]

16. Rozhkov, A.V.; Ivanov, D.M.; Novikov, A.S.; Ananyev, I.V.; Bokach, N.A.; Kukushkin, V.Y. Metal-involving halogen bond $\mathrm{Ar}-\mathrm{I} \cdots\left[\mathrm{d}_{\mathrm{z}} 2 \mathrm{Pt}^{\mathrm{II}}\right]$ in a platinum acetylacetonate complex. CrystEngComm 2020, 22, 554-563. [CrossRef]

17. You, F.; Paik, M.Y.; Häckel, M.; Kador, L.; Kropp, D.; Schmidt, H.W.; Ober, C.K. Control and suppression of surface relief gratings in liquid-crystalline perfluoroalkyl-azobenzene polymers. Adv. Funct. Mater. 2006, 16, 1577-1581. [CrossRef]

18. Priimagi, A.; Cavallo, G.; Metrangolo, P.; Resnati, G. The halogen bond in the design of functional supramolecular materials: Recent advances. Acc. Chem. Res. 2013, 46, 2686-2695. [CrossRef]

19. Berger, G.; Frangville, P.; Meyer, F. Halogen bonding for molecular recognition: New developments in materials and biological sciences. Chem. Commun. 2020, 56, 4970-4981. [CrossRef]

20. Loc Nguyen, H.; Horton, P.N.; Hursthouse, M.B.; Legon, A.C.; Bruce, D.W. Halogen bonding: A new interaction for liquid crystal formation. J. Am. Chem. Soc. 2004, 126, 16-17. [CrossRef]

21. Beale, T.M.; Chudzinski, M.G.; Sarwar, M.G.; Taylor, M.S. Halogen bonding in solution: Thermodynamics and applications. Chem. Soc. Rev. 2013, 42, 1667-1680. [CrossRef]

22. Erdelyi, M. Halogen bonding in solution. Chem. Soc. Rev. 2012, 41, 3547-3557. [CrossRef]

23. Bolton, O.; Lee, K.; Kim, H.-J.; Lin, K.Y.; Kim, J. Activating efficient phosphorescence from purely organic materials by crystal design. Nat. Chem. 2011, 3, 205-210. [CrossRef]

24. Gao, H.Y.; Zhao, X.R.; Wang, H.; Pang, X.; Jin, W.J. Phosphorescent cocrystals assembled by 1,4-diiodotetrafluorobenzene and fluorene and its heterocyclic analogues based on C-I $\cdots \pi$ halogen bonding. Cryst. Growth Des. 2012, 12, 4377-4387. [CrossRef]

25. Priimagi, A.; Saccone, M.; Cavallo, G.; Shishido, A.; Pilati, T.; Metrangolo, P.; Resnati, G. Photoalignment and surface-relief grating formation are efficiently combined in lowmolecular-weight halogen-bonded complexes. Adv. Mater. 2012, 24, OP345-OP352. [CrossRef]

26. Kravchenko, A.; Shevchenko, A.; Ovchinnikov, V.; Priimagi, A.; Kaivola, M. Optical interference lithography using azobenzene-functionalized polymers for micro- and nanopatterning of silicon. Adv. Mater. 2011, 23, 4174-4177. [CrossRef] 
27. Priimagi, A.; Cavallo, G.; Forni, A.; Gorynsztejn-Leben, M.; Kaivola, M.; Metrangolo, P.; Milani, R.; Shishido, A.; Pilati, T.; Resanti, G.; et al. Halogen bonding versus hydrogen bonding in driving self-assembly and performance of light-responsive supramolecular polymers. Adv. Funct. Mater. 2012, 22, 2572-2579. [CrossRef]

28. Bonanno, N.M.; Lough, A.J.; Lemaire, M.T. A trinuclear nickel(II) cluster containing a ditopic redox active ligand: Structural and magnetic properties. Polyhedron 2020, 183, 114536. [CrossRef]

29. Dutta, B.; Akhtaruzzaman, S.H.; Akitsu, T.; Slawin, A.M.Z.; Kar, U.; Sinha, C.; Mir, M.H. Two acetylenedicarboxylato-bridged 4-styrylpyridine appended 1D coordination polymers: Synthesis, structural characterization and variable temperature magnetism. J. Chem. Sci. 2020, 132, 9. [CrossRef]

30. Bertani, R.; Sgarbossa, P.; Venzo, A.; Lelj, F.; Amati, M.; Resnati, G.; Pilati, T.; Metrangolo, P.; Terraneo, G. Halogen bonding in metal-organic-supramolecular networks. Coord. Chem. Rev. 2010, 254, 677-695. [CrossRef]

31. Li, B.; Zhang, S.-Q.; Wang, L.-Y.; Mak, T.C.W. Halogen bonding: A powerful, emerging tool for constructing high-dimensional metal-containing supramolecular networks. Coord. Chem. Rev. 2016, 308, 1-21. [CrossRef]

32. Gamekkanda, J.C.; Sinha, A.S.; Desper, J.; Đaković, M.; Aakeröy, C.B. The Role of Halogen Bonding in Controlling Assembly and Organization of Cu (II)-Acac Based Coordination Complexes. Crystals 2017, 7, 226. [CrossRef]

33. Espallargas, G.M.; Brammer, L.; Sherwood, P. Designing intermolecular interactions between halogenated peripheries of inorganic and organic molecules: Electrostatically directed $\mathrm{M}-\mathrm{X} \cdots \mathrm{X}^{\prime}-\mathrm{C}$ halogen bonds. Angew. Chem. Int. Ed. 2006, 45, 435-440. [CrossRef]

34. Braga, D.; Grepioni, F.; Maini, L. The growing world of crystal forms. Chem. Commun. 2010, 46, 6232-6242. [CrossRef]

35. Friščić, T.; Jones, W. Recent advances in understanding the mechanism of cocrystal formation via grinding. Cryst. Growth Des. 2009, 9, 1621-1637. [CrossRef]

36. Schultheiss, N.; Newman, A. Pharmaceutical Cocrystals and Their Physicochemical Properties. Cryst. Growth Des. 2009, 9, 2950-2967. [CrossRef]

37. Wood, P.A.; Feeder, N.; Furlow, M.; Galek, P.T.A.; Groom, C.R.; Pidcock, E. Knowledge-based approach to crystal design. CrystEngComm 2014, 16, 5839-5848. [CrossRef]

38. Clemente-Juan, J.M.; Coronado, E.; Espallargas, G.M.; Adams, H.; Brammer, L. Effects of Halogen Bonding in Ferromagnetic chains on Co(II) coordination polymers. CrystEngComm 2010, 12, 2339-2342. [CrossRef]

39. Imakubo, T.; Kobayashi, M. Effects of solvent additives on the crystal architecture of supramolecular conductors based on diiodo(ethylenedithio)tetraselenafulvalene and indium tetrahalide anions. Eur. J. Inorg. Chem. 2014, 3973-3981. [CrossRef]

40. Pfrunder, M.C.; Micallef, A.S.; Rintoul, L.; Arnold, D.P.; McMurtrie, J. Interplay between the supramolecular motifs of polypyridyl metal complexes and halogen bond networks in cocrystals. Cryst. Growth Des. 2016, 16, 681-695. [CrossRef]

41. Ghosh, B.N.; Lahtinen, M.; Kalenius, E.; Mal, P.; Rissanen, K. 2,2':6' ,2"-terpyridine trimethylplatinum(Iv) iodide complexes as bifunctional halogen bond acceptors. Cryst. Growth Des. 2016, 16, 2527-2534. [CrossRef]

42. Cinčić, D.; Friščić, T. Synthesis of an extended halogen-bonded metal-organic structure in a one-pot mechanochemical reaction that combines covalent bonding, coordination chemistry and supramolecular synthesis. CrystEngComm 2014, 16, 10169-10172. [CrossRef]

43. Nemec, V.; Fotović, L.; Friščić, T.; Cinčić, D. A large family of halogen-bonded cocrystals involving metal-organic building blocks with open coordination sites. Cryst. Growth Des. 2017, 17, 6169-6173. [CrossRef]

44. Merkens, C.; Pan, F.; Englert, U. 3-(4-pyridyl)-2,4-pentanedione-A bridge between coordinativve, halogen, and hydrogen bonds. CrystEngComm 2013, 15, 8153-8158. [CrossRef]

45. Pfrunder, M.C.; Brock, A.J.; Brown, J.J.; Grosjean, A.; Ward, J.; McMurtrie, J.C.; Clegg, J.K. A three-dimensional cubic halogen-bonded network. Chem. Commun. 2018, 54, 3974-3976. [CrossRef]

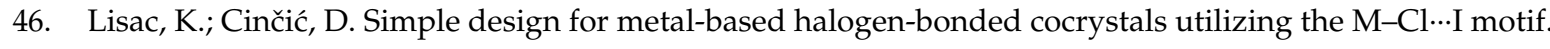
CrystEngComm 2018, 20, 5955-5963. [CrossRef]

47. Lisac, K.; Cinčić, D. The influence of liquid on the outcome of halogen-bonded metal-organic materials synthesis by liquid assisted grinding. Crystals 2017, 7, 363. [CrossRef] 
48. Lapadula, G.; Judaš, N.; Friščić, T.; Jones, W. A Three-Component Modular Strategy to Extend and Link Coordination Complexes by Using Halogen Bonds to $O, S$ and $\pi$ Acceptors. Chem. Eur. J. 2010, 16, 7400-7403. [CrossRef]

49. Nemec, V.; Piteša, T.; Friščić, T.; Cinčić, D. The morpholinyl oxygen atom as an acceptor site for halogen-bonded cocrystallization of organic and metal-organic units. Cryst. Growth Des. 2020. [CrossRef]

50. Cini, R.; Moore, S.J.; Marzilli, L.G. Strong Trans Influence Methoxymethyl Ligand in $B_{12}$ Cobaloxime and Imine/Oxime Model Complexes: Structural, Spectroscopic, and Molecular Mechanics Investigations. Inorg. Chem. 1998, 37, 6890-6897. [CrossRef]

51. Charland, J.P.; Zangrando, E.; Bresciani-Pahor, N.; Randaccio, L.; Marzilli, L.G. Binding of the lopsided 1,5,6-trimethylbenzimidazole ligand to inorganic and organometallic cobaloxime B12 models. Inorg. Chem. 1993, 32, 4256-4267. [CrossRef]

52. Schrauzer, G.N. Organocobalt chemistry of vitamin B12 model compounds. Acc. Chem. Res. 1968, 1, 97-103. [CrossRef]

53. Bresciani-Pahor, N.; Forcolin, M.; Marzilli, L.G.; Randaccio, L.; Summers, M.F.; Toscano, P.J. Organocobalt $\mathrm{B}_{12}$ models: Axial ligand effects on the structural and coordination chemistry of cobaloximes. Coord. Chem. Rev. 1985, 63, 1-125. [CrossRef]

54. Chen, J.; Sit, P.H.-L. Thermodynamic Properties of Hydrogen-Producing Cobaloxime Catalysts: A Density Functional Theory Analysis. ACS Omega 2019, 4, 582-592. [CrossRef] [PubMed]

55. Liu, W.-Q.; Lei, T.; Zhou, S.; Yang, X.-L.; Li, J.; Chen, B.; Sivaguru, J.; Tung, C.-H.; Wu, L.-Z. Cobaloxime Catalysis: Selective Synthesis of Alkenylphosphine Oxides under Visible Light. J. Am. Chem. Soc. 2019, 141, 13941-13947. [CrossRef] [PubMed]

56. Groom, C.R.; Bruno, I.J.; Lightfoot, M.P.; Ward, S.C. The Cambridge Structural Database. Acta Cryst. B 2016, 72, 171-179. [CrossRef]

57. Rubin-Preminger, J.M.; Englert, U. Halogen bonding in substituted cobaloximes. Inorg. Chim. Acta 2009, 362, 1135-1142. [CrossRef]

58. CrysAlis CCD; V171.34, Oxford Diffraction 2003; Oxford Diffraction Ltd.: Abingdon, UK, 2003.

59. CrysAlis RED; V171.34, Oxford Diffraction 2003; Oxford Diffraction Ltd.: Abingdon, UK, 2003.

60. Sheldrick, G.M. A short history of SHELX. Acta Cryst. A 2008, 64, 112-122. [CrossRef]

61. Sheldrick, G.M. SHELXT_-Integrated space-group and crystal-structure determination. Acta Cryst. A 2015, 71, 3-8. [CrossRef]

62. Farrugia, L.J. WinGX suite for small-molecule single-crystal crystallography. J. Appl. Cryst. 1999, 32, 837-838. [CrossRef]

63. Macrae, C.F.; Bruno, I.J.; Chisholm, J.A.; Edgington, P.R.; McCabe, P.; Pidcock, E.; Rodriguez-Monge, L.; Taylor, R.; van de Streek, J.; Wood, P.A. Mercury CSD 2.0-New features for the visualization and investigation of crystal structures. J. Appl. Cryst. 2008, 41, 466-470. [CrossRef]

64. Philips X'Pert Data Collector 1.3e; Philips X'Pert Graphics E Identify 1.3e; Philips X'Pert Plus 1.0; Philips Analytical B.V.: Lelyweg, The Netherlands, 1999.

65. Degen, T.; Sadki, M.; Bron, E.; König, U.; Né>nert, G. The highScore suite. Pow. Diff. 2014, 29 , S13-S18. [CrossRef]

66. STARe Software, v.15.00; Mettler Toledo: Greifensee, Switzerland, 2016.

67. Spackman, M.A.; McKinnon, J.J. Fingerprinting Intermolecular Interactions in Molecular Crystals. CrystEngComm 2002, 4, 378-392. [CrossRef]

(C) 2020 by the authors. Licensee MDPI, Basel, Switzerland. This article is an open access article distributed under the terms and conditions of the Creative Commons Attribution (CC BY) license (http://creativecommons.org/licenses/by/4.0/). 